\title{
Studi Keandalan Sistem Jaringan Distribusi 20 kV Dari Gangguan Faktor Alam di PT. PLN (PERSERO) Rayon Cimahi Selatan
}

\author{
Teguh Arfianto, Wahyu Agung Purbandoko \\ Jurusan Teknik Elektro \\ Institut Teknologi Nasional \\ Bandung, Indonesia \\ teguh.arfianto@gmail.com,wahyu78agung@gmail.com
}

\begin{abstract}
Abstrak-Permintaan kebutuhan energi listrik di wilayah Kota Cimahi khususnya di wilayah Cimahi Selatan semakin bertambah dari waktu ke waktu sejalan dengan meningkatnya pertumbuhan ekonomi. Hingga saat ini, energi listrik merupakan salah satu sumber energi yang utama untuk mendukung aktivitas tersebut. Pemanfaatan energi listrik yang ada harus diimbangi dengan menjaga kualitas energi listrik itu sendiri. Upaya yang diperlukan untuk memenuhi pertumbuhan energi listrik tidak hanya memenuhi permintaan daya yang meningkat setiap tahun tetapi juga memperbaiki mutu keandalan pelayanan. Jaringan distribusi merupakan bagian dari sistem tenaga listrik yang paling dekat dengan pelanggan dan yang paling banyak mengalami gangguan, sehingga salah satu masalah utama dalam operasi sistem distribusi adalah mengatasi gangguan, sebab terjadinya banyak gangguan akan mempengaruhi indeks keandalan. Pada laporan ini, dilakukan perhitungan keandalan jaringan distribusi untuk mencari nilai indeks keandalan pada satu penyulang (feeder)dalam satu rayon yang betempat di PT. PLN (PERSERO) rayon Cimahi Selatan. Perhitungan ini berdasarkan nilai laju kegagalan $(\lambda)$ dan lama perbaikan (r) dari masing-masing komponen yang digunakan dalam jaringan distribusi radial. Jumlah elemen atau komponen yang digunakan dan panjangnya jaringan akan mempengaruhi hasil nilai indeks keandalan. Penyulang yang dianalisis diambil dari Rayon Cimahi Selatan yaitu penyulang TOKYO. Hasil perhitungan menunjukkan total nilai SAIFI, SAIDI dan ASAI dalam kurun waktu satu tahun (2017) untuk penyulang TOKYO sebesar SAIFI 0,367 kali/tahun, SAIDI 2,62 menit/tahun dan ASAI 0,99\%. Sedangkan pada standar yang ditargetkan oleh PT.PLN Rayon tersebut sebesar: SAIFI 0,91 kali/tahun, sedangkan SAIDI sebesar 35,73 menit/tahun. Maka pada penyulang TOKYO masih dikatakan andal untuk mendistribusikan listrik karena nilai perhitungan masih dibawah target yang telah ditetapkan.
\end{abstract}

Kata-Kunci : Sistem Distribusi, Keandalan, SAIFI, SAIDI, ASAI

\section{PENDAhULUAN}

Sistem distribusi tenaga listrik PT. PLN (PERSERO) Rayon Cimahi Selatan yang bertegangan 20kV. Pada PT. PLN rayon Cimahi Selatan mempunyai jumlah penyulang (feeder) sebanyak 34 feeder [1] dan memiliki jumlah pelanggan sebanyak 112.749 konsumen. Sebagai peralatan yang dapat menyalurkan energi listrik secara andal dan terus menerus dari sistem transmisi menuju beban dan pelanggan. Kendalan menggambarkan suatu ukuran tingkat atau pelayanan penyedia tenaga listrik dari sistem ke menuju beban pelanggan. Keandalan sistem distribusi tenaga listrik sangat di pengaruhi oleh konfigurasi sistem [2]. Sistem yang di harapkan haruslah kontinu dan ketersedian untuk konsumen tidak terganggu, bagaimana pun suatu sistem dapat terganggu dengan berbagai masalah yang mengakibatkan penyaluran listrik terganggu atau terputus ke konsumen.

Untuk mengetahui keandalan suatu sistem maka ditetapkan pada indeks keandalan, pada dasarnya adalah suatu angka atau parameter yang menunjukkan tingkat pelayanan atau tingkat keandalan dari suplai tenaga listrik sampai ke konsumen. Indeks-indeks keandalan yang sering dipakai dalam suatu sistem distribusi adalah SAIFI (System Average Interruption Frequency Index), SAIDI (System Average Interruption Duration Index) [3].

Pada penelitian ini bertujuan untuk mencari indeks nilai SAIDI dan SAIFI pada PT. PLN (PERSERO) Rayon Cimahi Selatan pada penyulang TOKYO dan membandingakan dengan nilai standar yang ditargetkan oleh PT. PLN tersebut selama satu periode.

\section{TINJAUAN PUSTAKA}

\section{A. Definisi Indeks Keandalan}

Untuk mengukur tingkat keandalan dari tiap-tiap titik beban/load point digunakan indeks-indeks keandalan dasar antara lain :

$\lambda=$ Frekuensi kegagalan tahunan rata-rata (fault/year)

$\mathrm{r}=$ Lama terputusnya pasokan listrik rata-rata (hours/fault)

$\mathrm{U}=$ Lama/durasi terputusnya pasokan listrik tahunan ratarata (hours/year)

Berdasarkan indeks-indeks keandalan dasar ini, bisa diperolehindeks keandalan untuk sejumlah titik 
beban/load point, yang selanjutnya digunakan untuk menentukan indeks keandalan sistem secara keseluruhan. Indeks-indeks keandalan sistem yang penting antara lain:

1. SAIFI (System Average Interruption Frequency Index)

SAIFI adalah salah satu indeks keandalan dimana prhitungannya adalah perkalian frekwensi padam sebuah penyulang dengan jumlah pelanggan yang mengalami gangguan pemadaman dibagi dengan jumlah pelanggan secara keseluruhan. Satuan dari perhitungan indeks SAIFI adalah pemadaman per pelanggan. Perhitungan pemadaman dapat dilakukan dalam jangka waktu tertentu, baik hari, bulan maupun tahun. Secara matematis indek SAIFI dapat dirumuskan sebagai berikut [4]:

$$
\text { SAIFI }=\frac{\text { Jumlah Padam dikonsumen }}{\text { Total konsumen }}
$$

Untuk menghitung indeks diatas, persamaannya adalah [7]

$$
S A I F I=\frac{\sum \lambda i}{\sum M i}
$$

dengan:

$\lambda \dot{i}=$ Frekuensi kegagalan/failure rata-rata tahunan

$M i=$ Jumlah konsumen

\section{SAIDI (System Average Interruption Duration Index)}

SAIDI adalah indeks keandalan yang merupakan perkalian dari lamanya suatu sistem padam dalam hitungan jam dengan banyaknya pelanggan yang mengalami pemadaman dibagi dengan jumlah pelanggan keseluruhan. Satuan perhitungan SAIDI adalah jam/pelanggan. Dengan indeks ini, gambaran mengenai lama pemadaman rata-rata yang diakibatkan oleh gangguan pada bagian-bagian dari sistem dapat dievaluasi. Secara matematis dapat dirumuskan sebagai berikut [4]-[8]:

$$
\text { SAIDI }=\frac{\text { Jumlah Lamanya Padam dikonsumen }}{\text { Total konsumen }}
$$

Untuk menghitung indeks diatas, persamaannya adalah [7] :

$$
S A I D I=\frac{\Sigma V i \cdot M i}{\Sigma M i}
$$

dengan:

$V i=$ Lama/durasi terputusnya pasokan listrik tahunan rata-rata (hours/year).

$\mathrm{Mi} \quad=$ Jumlah konsumen.

\section{ASAI (Average System Avaibility Index)}

ASAI merupakan suatu indeks yang menyatakan kemampuan suatu sistem untuk menyediakan/menyuplai suatu sistem dalam jangka waktu 1 tahun.

Berikut ini adalah rumus persamaan untuk menghitung indeks keandalan ASAI [5]:

$$
A S A I=\frac{\sum N i x 8760-\sum U i N i}{\sum N i x 8760}
$$

ASAI dapat juga dihitung dengan persamaan [8]:

$$
A S A I=\frac{8760-S A I D I}{8760}
$$

Keterangan:

8760 adalah jumlah jam dalam satu tahun.

Pada umumnya ASAI dinyatakan dalam persentase.

\section{B. Faktor Mempengaruhi Indeks Keandalan}

Untuk memahami faktor-faktor yang mempengaruhi indeks keandalan dalam suatu sistem distribusi yaitu [1]:

1. Gangguan/Outage . Keadaan dimana suatu komponen tidak dapat berfungsi sebagaimana mestinya, diakibatkan karena terjadi sesuatu yang berhubungan langsung dengan komponen tersebut. Suatu outage dapat atau tidak dapat mengakibatkankan pemadaman, hal ini masih tergantung pada konfigurasi sistem.

2. Kegagalan/Failure. Keadaan dimana suatu komponen tidak dapat berfungsi sebagaimana mestinya, diakibatkan karena terjadi malfunction pada komponen tersebut. Failure pada suatu komponen mengakibatkan outage pada komponen tersebut, tetapi outage pada suatu komponen dapat terjadi tanpa terjadinya failure pada komponen tersebut.

3. Rata-rata Gangguan/Outage Rate. Rata-rata jumlah outage per komponen selama periode tertentu, untuk klasifikasi outage dan jenis komponen tertentu.

4. Lama Gangguan/Outage Duration. Periode dari saat suatu komponen mulai mengalami outage sampai saat dapat dioperasikan kembali sesuai dengan fungsinya.

5. Switching Time. Periode dari saat suatu operasi switching diperlukan akibat forced outage sampai saat operasi switching tersebut dilakukan.

6. Pemadaman/Interruption of Supply. Terhentinya pelayanan pada satu atau lebih konsumen, akibat dari satu atau lebih komponen mendapat gangguan.

7. Lama pemadaman/Interruption Duration. Waktu dari saat terjadinya pemadaman sampai saat menyala kembali.

8. Jumlah total komsumen terlayani/Total Number of Customer Served. Jumlah total dari konsumen yang terlayani sesuai dengan periode laporan terakhir .

9. Periode laporan. Periode laporan diasumsikan sebagai satu tahun.

\section{METODE PENELITIAN}

Adapun tahapan yang dilakukan untuk melakukan penelitian ini adalah :

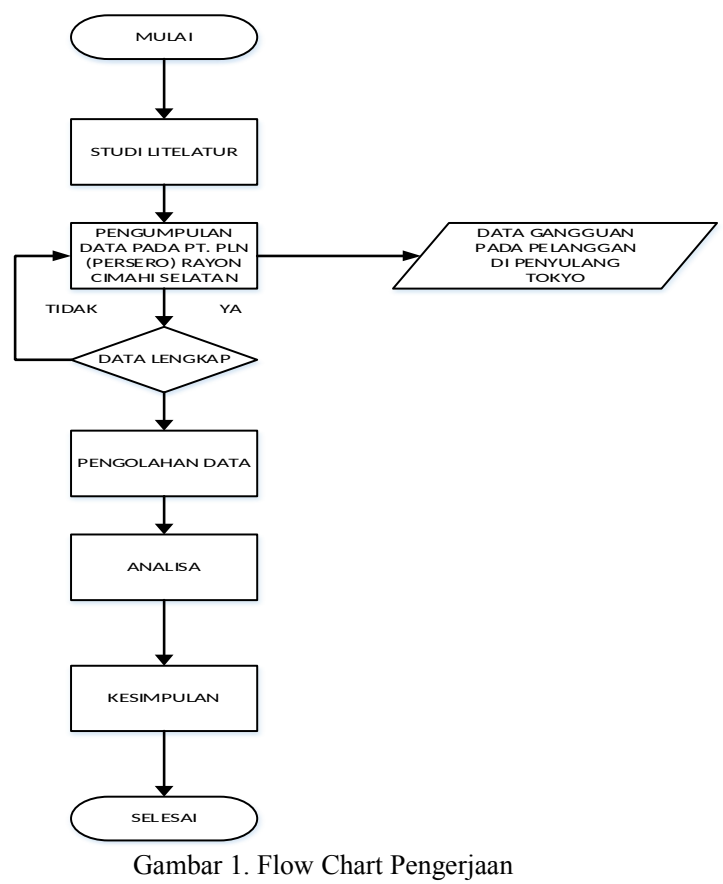




\section{HASIL PENGERJAAN DAN ANALISIS}

\section{A. Pembahasan}

Pada penelitian ini penulis membahas tentang keandalan system distribusi pada saluran kabel tegangan menengah (SUTM) pada penyulang Tokyo yang disebabkan oleh factor gangguan alam. Pada penelitian ini penulis mendapatkan beberapa factor yang mempengaruhi keandalan system di penyulang tersebut yang disebabkan oleh alam yaitu:

1. Gangguan pihak ke-3, dimana yang menyebabkan gangguan pada jalur ini disebabkan oleh tumbangnya pohon sehingga menyebabkan padamnya aliran listrik.

2. Gangguan yang disebabkan oleh factor kesalahan manusia (human error), pada penyulang ini terjadi beberapa kali gangguan yang disebabkan oleh kesalahan manusia yang dikarenakan terkenanya kabel SUTM oleh galian.

3. Gangguan yang dipengaruhi oleh kondisi cuaca, dalam gangguan ini dikarenakan lembabnya kubikel sehingga menyebabkan padam.

\section{B. Data Gangguan}

Untuk melihat keandalan system distribusi di penyulang TOKYO di tahun 2017 maka diharuskan untuk melihat data gangguan yang terjadi pada penyulang tersebut. Maka didapat data sebagai berikut :

Tabel 1. Data Gangguan di Penyulang TOKYO

\begin{tabular}{|c|c|c|c|c|c|}
\hline No & Tanggal & $\begin{array}{l}\text { Lama } \\
\text { Padam } \\
\text { (JAM) }\end{array}$ & $\begin{array}{l}\text { Beban } \\
\text { Padam }\end{array}$ & $\begin{array}{l}\text { Jumlah Total Durasi } \\
\text { Gangguan Konsumen } \\
\text { (JAM) }\end{array}$ & LOKASI \\
\hline l. & $4-\operatorname{Jan}-17$ & $0: 45$ & 149 & 67,05 & $\begin{array}{l}\text { Gangruan Pihak ke } 3 \text { di } \\
\text { Gd. BM (Rohon Tumbang) }\end{array}$ \\
\hline 2. & $29-\mathrm{Jan}-17$ & $0: 37$ & 177 & 65,49 & $\begin{array}{l}\text { SKTM antara Gd. BCAD- } \\
\text { Gd. BB }\end{array}$ \\
\hline 3. & $16-\mathrm{Mar}-17$ & $0: 26$ & 182 & 47,32 & $\begin{array}{l}\text { Gangguan pihak ke } 3 \text { ( Gd. } \\
\text { GLL) (Pohon Tumbang) }\end{array}$ \\
\hline 4. & $11-A g s-17$ & $0: 01$ & 178 & 2,18 & $\begin{array}{l}\text { SKTM antara Gd. BIPA - } \\
\text { GH CBBRU } \\
\text { (KEBELINCONG) }\end{array}$ \\
\hline 5. & $30-A g n-17$ & $0: 01$ & 182 & 2,22 & $\begin{array}{l}\text { SKTM antara Gd. ABT - } \\
\text { DPZ }\end{array}$ \\
\hline 6. & $09-\operatorname{Sep}-17$ & $0: 01$ & 63 & 1,03 & $\begin{array}{l}\text { SKTM antara Gd. HHS - } \\
\text { CTB ( KEBELINCONG) }\end{array}$ \\
\hline 7. & $20-0.15 t-17$ & $0: 02$ & 139 & 3,18 & $\begin{array}{l}\text { SKTM antara Gd BCAJ - } \\
\text { BM(KENA BEKHOE) }\end{array}$ \\
\hline 8. & $25-0.0 \mathrm{st}-17$ & $0: 02$ & 182 & 4,04 & $\begin{array}{l}\text { SKTM antara Cod BCAJ - } \\
\text { BM(KENA BEKHOE) }\end{array}$ \\
\hline 9. & $03-0.01 t-17$ & $0: 03$ & 63 & 2,29 & SKTM antara Gd BM - CL \\
\hline 10. & $16-0.15 t-17$ & $0: 01$ & 72 & 1,12 & $\begin{array}{l}\text { SKTM antara Gd CL - Gd } \\
\text { KTKS (KENA BEKHOE } \\
\text { ) }\end{array}$ \\
\hline 11. & $27-0.0 \mathrm{st}-17$ & $0: 02$ & 85 & 2,10 & $\begin{array}{l}\text { SKTM antara Gd. CTB - } \\
\text { HSS (KENA PAKU } \\
\text { BUMI) }\end{array}$ \\
\hline
\end{tabular}

Tabel 1 Lanjutan

\begin{tabular}{|c|c|c|c|c|}
\hline 12. $03-\mathrm{Nov}-17$ & $0: 26$ & 72 & 19,12 & Kubikel lembab \\
\hline \multirow{3}{*}{ 13. $04-\mathrm{Nov}-17$} & \multirow{3}{*}{$0: 01$} & \multirow{3}{*}{64} & \multirow{3}{*}{1,04} & SKTM antara Sid CL - \\
\hline & & & & KTKS (KENA BEKHOE \\
\hline & & & & ) \\
\hline \multirow{2}{*}{$20-\mathrm{Nov}-17$} & \multirow{2}{*}{$0: 02$} & \multirow{2}{*}{180} & \multirow{2}{*}{4} & SKTM antara Gd BCAJ - \\
\hline & & & & BM (KENA BEKHOE) \\
\hline \multirow{3}{*}{ 15. $24-\mathrm{Nov}-17$} & \multirow{3}{*}{$0: 02$} & \multirow{3}{*}{65} & \multirow{3}{*}{1,30} & SKTM antara Gd KTKS- \\
\hline & & & & BCAD ( KENA \\
\hline & & & & BEKHOE) \\
\hline & & & & SKTM antara Gd CL- \\
\hline 16. 24-Nov-17 & $0: 02$ & 110 & 2,20 & KTKS ( KENA BEKHOE \\
\hline
\end{tabular}

\section{Data Jumlah Konsumen}

Jumlah konsumen pada penyulang TOKYO di PLN rayon Cimahi Selatan berjumlah :

Tabel 2 Data konsumen di Penyulang TOKYO

\begin{tabular}{ccc}
\hline No. & Bulan & Jumlah Konsumen \\
\hline $\mathbf{1 .}$ & Januari & 5226 \\
\hline $\mathbf{2 .}$ & Maret & 5279 \\
\hline $\mathbf{3 .}$ & Agustus & 5299 \\
\hline $\mathbf{4 .}$ & September & 5326 \\
\hline $\mathbf{5 .}$ & Oktober & 5354 \\
\hline $\mathbf{6 .}$ & November & 5392 \\
\hline
\end{tabular}

\section{Pengolahan Data}

Dalam pengolahan data ini penulis mencari perhitungan untuk indek frequensi gangguan system (SAIFI) dan durasi gangguan sistem (SAIDI).

1. SAIFI (System Average Interruption Frequency Index)

Rekapan nilai SAIFI pada setiap bulannya adalah sebagai berikut :

Tabel 3 Nilai SAIFI di Penyulang TOKYO

\begin{tabular}{ccc}
\hline No. & Bulan & Nilai SAIFI \\
\hline 1. & Januari & 0,063 \\
\hline 2. & Maret & 0,034 \\
\hline 3. & Agustus & 0,067 \\
\hline 4. & September & 0,012 \\
\hline 5. & Oktober & 0,1 \\
\hline 6. & November & 0,091 \\
\hline Total SAIFI pertahun & 0,367 \\
\hline
\end{tabular}


Maka nilai SAIFI yang didapat dalam jangka waktu satu tahun adalah 0,367 gangguan/tahun.pelanggan

\section{SAIDI (System Average Interruption Duration Index)}

Rekapan nilai SAIDI pada setiap bulannya adalah sebagai berikut :

Tabel 3 Nilai SAIDI di Penyulang TOKYO

\begin{tabular}{ccc}
\hline No. & Bulan & Nilai SAIDI \\
\hline $\mathbf{1 .}$ & Januari & 1,52 \\
\hline $\mathbf{2 .}$ & Maret & 0,54 \\
\hline $\mathbf{3 .}$ & Agustus & 0,05 \\
\hline $\mathbf{4 .}$ & September & 0,06 \\
\hline $\mathbf{5 .}$ & Oktober & 0,14 \\
\hline $\mathbf{6 .}$ & November & 0,31 \\
\hline
\end{tabular}

\section{ASAI}

ASAI merupakan suatu indeks yang menyatakan kemampuan suatu sistem untuk menyediakan/menyuplai suatu sistem dalam jangka waktu 1 tahun.

$$
\text { ASAI }=\frac{8760-2,62}{8760}=0,99 \%
$$

\section{ANALISA DATA}

Setelah melakukan penelitian ini maka ada beberapa hal yang dapat dianalisis, yaitu:

Pada penyulang tokyo ini sering terjadi gangguan yang disebabkan oleh terkena benturan saluran kabel tegangan menengah (SUTM) oleh galian drainase.

Index saifi adalah untuk menentukan tingkat keandalan suatu sistem tersebut dengan melihat berapa kali kejadian gangguan yang terjadi selama satu tahun, lalu hasil tersebut dibandingkan dengan standar yang ada pada Rayon Cimahi Selatan. Maka didapat perbandingannya adalah :

\begin{tabular}{cc}
\hline Hasil perhitungan Saifi & Standar Saifi Rayon Cimahi Selatan \\
\hline $\mathbf{0 , 3 6 7}$ & 0,91 \\
\hline
\end{tabular}

Maka penyulang Tokyo di rayon cimahi selatan masih bisa dikatakan andal dikarenakan nilai gangguan yang terjadi dalam kurun waktu 1 tahun masih dibawah nilai yang di tetapkan di rayon Cimahi Selatan.

Index Saidi adalah untuk melihat lamanya gangguan dalam waktu satu tahun. Pada hasil perhitungan Saidi yang terjadi di penyulang Tokyo didapatkan nilai sebesar :

\begin{tabular}{cc}
\hline Hasil perhitungan Saidi & $\begin{array}{c}\text { Standar Saidi Rayon Cimahi } \\
\text { Selatan }\end{array}$ \\
\hline 2,62 & 35,73
\end{tabular}

Setelah dibandingkan maka nilai saidi yang terjadi dalam satu tahun masih dibawah standar yang di targetkan oleh Rayon Cimahi Selatan. Maka sistem tersebut masih bisa dikatakan andal.

Untuk mengurangi nilai saidi dan saifi dapat dilakukan dengan cara perbaikan pada saluran SKTM penyulang tersebut. Perbaikan yang dapat dilakukan adalah membuat jalur tersendiri untuk SKTM agar tidak berbenturan dengan jalur drainase, dan memberikan tanda jalur SKTM tersebut. Apabila gangguan yang disebabkan oleh human eror ini bisa diatasi akan mendapatkan data seperti (asumsikan gangguan yang terjadi sama dengan periode 2017).

Dan mendapatkan nilai saidi dan saifi sebesar

Saidi $=0,03$ jam $/$ (tahun.pelanggan) $=1,8$ menit $/$ (tahun.pelanggan).

Saifi $=0,076$ gangguan(tahun.pelanggan).

Sehingga dapat mengurangi nilai gangguan sebesar $20,7 \%$ (pada nilai Saifi) dan 69,4\% (pada nilai Saidi).

\section{KESIMPULAN}

Berdasarkan data dan analisis yang telah dilakukan, maka didapatkan hasil sebagi berikut :

1. Dari data gangguan yang terjadi dalam kurun waktu satu tahun di penyulang tokyo ini mendapatkan nilai saifi sebesar 0,367 gangguan/pelanggan dan setelah dibandingkan dengan standar di rayon Cimahi selatan maka sistem masih dikatakan andal dikarenakan dibawah nilai stadarnya.

2. Dan pada nilai saidi didapatkan sebesar 2,592 menit/pelanggan dan nilai tersebut masih dibawah nilai yang telah di tetapkan oleh Rayon Cimahi Selatan dan dapat dikatakan andal.

\section{UCAPAN TERIMA KASIH}

Penulis mengucapkan terima kasih kepada Bapak Ilyas selaku pembimbing di PT. (PERSERO) PLN Rayon Cimahi Selatan yang telah memberi banyak ilmu mengenai keandalan sistem distribusi. Kepada Bapak Teguh Arfianto S.T., M.T. selaku pembimbing di Itenas, atas waktu yang diberikan, masukan, saran, juga bimbingan.

\section{DAFTAR PUSTAKA}

[1] Tanjung Abrar. 2012. AnalisIs Sistem Distribusi $20 \mathrm{kV}$ Untuk Memperbaiki Kinerja Dan Keandalan Sistem Distribusi Menggunakan Electrical Transient Analisys Program. ITENAS

[2] Suswanto, Daman. Bab 13 Analisis Gangguan Pada Jaringan Distribusi Mubarak, Morhel. 2008. Stud Keterandalan Sistem Jaringan Distribus Udara $20 \mathrm{KV}$ pada Gardu Hubung Kandis Kota Padang. ITENAS.

[4] Erhaneli. (2015). Evaluasi Keandalan Sistem Distribusi Tenaga Listrik Berdasarkan Indeks Keandalan Saidi dan Saifi Pada PT.PLN (Persero) Rayon Bagan Batu. ITENAS.

[5] Rahmat, Gheschik Safiur (2013). Keandalan Sistem Distribusi. ITENAS.

[6] Perdana, M. Y, Utomo, I. T, \& Soekotjo, I. H (2014). Analisis Keandalan Sistem Distribusi Tenaga Listrik Penyulang Jember Kota dan Kalisat di PT. PLN APJ Jember. ITENAS.

[7] Saodah, S. (2008). Evaluasi Keandalan Sistem Distribusi Tenaga Listrik Berdasarkan Saidi dan Saifi. ITENAS.

[8] Veriyandi, R. (2014). Index Keandalan Sistem Jaringan Distribusi 20 KV di PT. PLN (PERSERO) Rayon Subang. Bandung: ITENAS. 